\title{
Novos caminhos teóricos e metodológicos para a investigação científica em Norbert Elias ${ }^{1}$.
}

\author{
Doacir Gonçalves de Quadros ${ }^{2}$
}

Os primeiros livros de Norbert Elias (1897-1990) foram publicados em português somente a partir de 1987. Entretanto, o desenvolvimento de sua vasta obra tem início desde 1930, e somente após 1970 é que ela alcança amplo reconhecimento, inspirando novas pesquisas. Entre seus livros posso citar: a "Sociedade de Corte"(1933) publicada no Brasil em 1987, na qual Norbert Elias investiga a sociedade de corte, última grande formação não burguesa do Ocidente, como objeto de estudo sociológico para a compreensão de nossa própria sociedade. Neste trabalho ele procura responder à pergunta: qual era a estrutura do contexto social que permitiu o surgimento da formação social de corte? E quais as exigências que decorriam da estrutura social em relação aos homens e mulheres que a formavam? Para responder tais questões Norbert Elias analisa a divisão de oportunidades de poder, as necessidades criadas artificialmente pela configuração da sociedade de corte e as relações de dependência que possibilitaram a homens e mulheres reunir-se durante várias gerações sob o signo da formação social de corte. Formação esta que teve um caráter representativo central em maior parte dos países europeus nos séculos XVII e XVIII.

Já o livro "O Processo Civilizador", escrito na década de 1930 e publicado em português em 1990 e 1993 tem como tema fundamental os tipos de comportamento considerados típicos do homem civilizado ocidental. Procura, a partir daí, responder como ocorreu realmente essa mudança ou esse processo civilizador do Ocidente. Em que ele consistiu? E quais foram suas causas ou forças motivadoras? Em 1994 é publicado "A Sociedade dos Indivíduos", composto por três ensaios interrelacionados escritos entre 1939 e 1987. Norbert Elias aborda uma questão central neste livro: qual a relação entre a pluralidade de pessoas e a pessoa singular a que chamamos "indivíduo"; e a relação entre a pessoa singular com a pluralidade? Relacionando os termos "sociedade" e "indivíduos" ele deixa claro a que ponto cada pessoa é influenciada em seu desenvolvimento pela posição em que ocupa no fluxo do

\footnotetext{
${ }^{1}$ Este ensaio surgiu da necessidade de apresentá-lo ao final da disciplina Sociologia da Cultura, a qual tem como objetivo o estudo monográfico da obra do sociólogo alemão Norbert Elias (18971990) abordando as suas contribuições teóricas e metodológicas, como a teoria dos processos, a teoria das figurações, o conceito de sociogênese, a idéia de jogos, a questão do poder e Estado moderno e a discutível relação entre indivíduo e sociedade

${ }^{2}$ Graduação - Ciências Socias/UFPR.
} 
processo social. No mesmo ano de 1994 é publicado "Mozart - sociologia de um gênio", no qual Elias investiga o conflito trágico de uqe fez parte a criatividade pessoal em uma sociedade que pretendia controlá-la. Por fim, em 1997, é publicado "Os alemães- a luta pelo poder e a evolução do habitus nos séculos XIX e XX, e em 1999 "Os estabelecidos e os Outsiders" escrito em parceria com John Scotson.

As contribuições desenvolvidas por Norbert Elias em sua obra parecem, a meu ver, apontar novos caminhos teóricos e metodológicos para a pesquisa científica, em especial a do sociólogo. Dentro desta perspectiva crítica, de Elias, estaria ele abandonando aos paradigmas que até então orientavam a "ciência normal"? E se de fato tivermos esta ruptura, pode-se considerá-la como uma revolução científica? Para responder a estas questões, consultei duas obras que acredito facilitarem tal tarefa. São elas: "A estrutura das revoluções científicas" de Thomas S. Kuhn, escrita em 1962, de cunho epistemológico da Ciências Sociais, e o livro "Introdução à Sociologia" de Elias, escrito em 1969, este último uma síntese de suas contribuições teóricas e metodológicas que reúne aspectos de história política, de psicologia e de sociologia. Verei inicialmente como Thomas Kuhn chega à afirmação de que "uma comunidade científica ao adquirir um paradigma, adquire igualmente um critério para escolha de problemas, que enquanto o paradigma for aceito, poderemos considerar como dotados de uma solução possível'(KUHN,1962,p.60); assim como a afirmação de que abandonando tal paradigma, o pesquisador deixa de praticar a ciência que por ele é definida. Retomarei este tema após fazer um breve resumo das contribuições metodológicas e teóricas de Norbert Elias para a pesquisa científica sociológica.

Podemos definir epistemologicamente o termo "ciência normal", segundo Thomas Kuhn, como a pesquisa baseada em realizações científicas passadas, as quais são reconhecidas pela comunidade científica para a prática de seus fundamentos teóricos e metodológicos após atraírem um grupo duradouro de praticantes, e deixarem uma gama considerável de problemas para serem resolvidos pelo grupo de praticantes desta ciência. Assim, as realizações que partilham destas duas características estão estritamente ligadas ao termo "paradigmas compartilhados", pois seus realizadores estão comprometidos pelas mesmas regras e padrões, para a prática científica, criando um consenso e um comprometimento aparentes que são necessários para a gênese e a continuação de uma determinada tradição de pesquisa científica. Basicamente um paradigma, quando bem sucedido, atualiza e amplia o conhecimento dos fatos que considera pertinentes à pesquisa, permitindo melhor profundidade e detalhamento na investigação, fatores importantes para o melhor desenvolvimento da ciência. Para Kunh, temos três classes de 
problemas para investigação na "ciência normal"; são elas: a determinação do fato significativo, a harmonização dos fatos com a teoria, e por fim a articulação da teoria. Inevitavelmente, o trabalho orientado pelo paradigma só pode, de acordo com Kuhn, ser conduzido dessa forma. Abandonar tal paradigma é deixar de praticar a ciência, como ele a define. Quando ocorre o abandono de um paradigma em substituição por outro mais novo, ocorrem as "revoluções científicas", durante as quais os pesquisadores serão guiados para novas direções, por novos instrumentos.

No livro "Introdução à Sociologia", publicado em português em 1999, Elias escreve sobre o papel do sociólogo como destruidor de mitos, das características universais da sociedade humana e da teoria do desenvolvimento social. A sua tarefa central seria demonstrar a autonomia da sociologia frente às demais ciências da época, em especial da psicologia e da biologia. Basicamente ele retoma a tarefa que Augusto Comte (1798-1851) reconheceu, mas não verificou cientificamente, através de de modelos teóricos. Elias aplica seus modelos de interpenetração e de indivíduos interdependentes para mostrar um nível de integração no qual as formas de organização, processos e estruturas, não podem ser deduzidos das características biológicas e psicológicas que formam os indivíduos.

A autonomia da sociologia em relação à biologia, à psicologia e à física, se encontra para Elias no seu campo de estudo, que não se explica se estudarmos os seres humanos isoladamente, mas sim as "configurações de seres humanos interdependentes" entendido por ele como "o padrão mutável criado pelo conjunto dos jogadores - não só pelos seus intelectos mas pelo que eles são no seu todo, a totalidade das suas ações nas relações que sustentam uns com os outros" (ELIAS,1999, p.142). A interdependência é para ele uma condição inicial da formação de uma configuração, que pode ser constituída de aliados ou adversários, gerando modelos aceitos como representações de seres humanos ligados uns aos outros no tempo espaço. Conceitos como poder, norma, valor, estrutura e função, classe social e sistema social, sociedade e indivíduo, devem ser tidos pelos sociólogos como categorias mutáveis e móveis. Isto porque a sociologia não deve fazer a redução processual de aquilo que observa como sendo móvel e mutável, a algo imutável e eterno. A autonomia da sociologia frente à biologia baseia-se no fato de que as pessoas seriam organismos que têm um caráter singular: são mutáveis por natureza. "Em resumo, a estrutura das sociedades compostas por criaturas não humanas só muda quando se altera a estrutura biológica dessas criaturas" (ELIAS,1999,p.117), porém as sociedades humanas podem mudar sem que ocorra alteração na constituição biológica do homem; como por exemplo, a transformação das sociedades pré-industriais em sociedades industriais. Para Elias, o caráter de tais mudanças sociais deve ser compreendido a partir do 
comportamento do homem, que representa o ajustamento a situações mutáveis por intermédio da aprendizagem individual - que atua por meio da acumulação de experiência. Elias sugere que não devemos, portanto, considerar a estabilidade e a imutabilidade como características normais de um sistema social, e nem a mudança como conseqüência de distúrbios do estado normal de equilíbrio das sociedades - como propôs o sociólogo funcionalista Talcott Parsons (1964), em seu livro "O sistema social". Devemos sim construir uma estrutura de referências para investigação em qualquer situação social concreta.

A reorientação do pensamento sociológico, sugerida por Norbert Elias, decorre da busca da autonomia da sociologia frente às demais ciências. $\mathrm{O}$ seu campo de estudo é as sociedades humanas, que têm como característica universal a mutabilidade, que se explicaria a partir da análise das configurações de seres humanos interdependentes. É fato que "a complexidade da muitas teorias sociológicas modernas deve-se não à complexidade do campo de investigação que elas procuram elucidar, mas ao tipo de conceitos usados" (ELIAS, 1999,p.121) que podem estar inadequados e ineficazes para a investigação de relações funcionais especificamente sociais. Portanto a sociologia, segundo Elias, não se resume a uma ciência generalizadora como quis Max Weber (1864-1920), que apresentou em sua teoria o estado, nação e a família como uma padrão particular da ação social das pessoas individuais. Weber insistia em transformar a sociedade numa massa de ações desordenadas, executadas por indivíduos independentes e autoconfiantes. Nesta sociedade as estruturas sociais como administrações burocráticas, sistemas econômicos capitalistas e tipos de domínios carismáticos seriam produtos artificiais dos sociólogos, que na realidade não responderiam a uma ordem e a uma estrutura. Ou, como Emile Durkheim (1858-1917) que, por outro lado, valorizou a sociedade em detrimento ao indivíduo - como destaca Elias citando uma passagem da Divisão do Trabalho Social (1893) ; "é uma verdade evidente que não há nada na vida social que não esteja nas consciências individuais. Contudo, o que encontramos nestas vem da sociedade" (ELIAS, 1999, p.128). E Talcott Parsons, que considerou tanto o indivíduo quanto a sociedade, porém isolou-os como se estivessem constantemente em repouso, sem interação um com o outro.

Segundo Norbert Elias, deve-se entender a relação indivíduo e sociedade como um conceito que se refere à pessoa no singular o outro a pessoas no plural respectivamente. Assim, a imagem do homem que é preciso para o estudo da sociologia não é o da pessoa no singular, mas sim a de pessoas no plural de modo a conceber a imagem de uma multidão de pessoas, cada uma delas formando um processo aberto e interdependente. Processo que constitui pessoas entre outras pessoas, envolvidas em jogos com outras pessoas, formando configurações que podem alterar-se no decorrer da evolução social 
por intermédio dos conflitos e tensões que constituem o centro do processo de evolução na teoria sociológica de Elias, conforme a sua citação "a ascensão e queda de grupos dentro das configurações e as tensões e conflitos estruturais concomitantes, são centrais em todos os processos evolutivos" (ELIAS,1999,p.191).

Um leitor atento percebe que na teoria sociológica de Norbert Elias o conceito de interdependências humanas está ocupando o seu centro , assim é possível perguntar o que faz as pessoas ligarem-se umas as outras se tornando dependentes umas das outras? Em um dos capítulos conclusivos de seu livro, Elias aponta as ligações afetivas, ocupacionais, políticas e econômicas como portadoras da função de unirem as pessoas em prol de objetivos comuns. Entretanto, estas ligações não são autônomas, inclusive a econômica que na concepção de Karl Marx (1818-1883) é autônoma e isolada com leis próprias dentro das relações funcionais de toda a sociedade. Na concepção marxista o desenvolvimento das instituições políticas é inerente a ampliação das redes de comércio e de indústria. E a luta pelo poder está reduzida em função da distribuição de possibilidades econômicas, resultado do equilíbrio de ganhos e perdas entre as trabalhadores e empresários industriais. Para Elias "é necessária uma concepção de classe que atenda ao fato de que as lutas funcionais e organizacionalmente interdependentes entre trabalhadores e patrões se processam a muitos outros níveis de integração que não os da fábrica" (ELIAS,1999,p.157), isto porque com o desenvolvimento da sociedade industrial as duas classes organizadas estão muito mais integradas nas organizações estatais, apesar da distribuição de poder entre elas no âmbito da fábrica ainda ser desigual. As classes industriais neste caso são dominantes e estão representadas em todos os diferentes níveis de integração da sociedade industrial (a nível local, regional e nacional). Portanto, surgem tensões além das localizadas por Karl Marx no âmbito da fábrica. Assim as tensões para Norbert Elias podem se concretizar entre governantes e governados, mas também entre pessoas que representam a mesma classe em diferentes níveis de integração.

Após este breve balanço das contribuições de Norbert Elias em que ele propõe uma nova justificação da sociologia partindo de idéias traçadas por Augusto Comte, para então retomar categorias básicas do pensamento sociológico dando continuidade a "tradição sociológica". Porém, como vimos, ele adota uma posição crítica a sociólogos clássicos do pensamento sociológico como Marx, Durkheim, Weber e Parsons, repensando conceitos como indivíduos, grupos entre outros. Se minha hipótese inicial propôs que Elias possibilitou novos caminhos teóricos e metodológicos para a investigação científica, creio que ela esteja correta, isto porque nas palavras do autor "se, ao escrevermos uma introdução à sociologia, nos desviamos um pouco dos caminhos usuais e, ao fazê-lo, tentamos ajudar o leitor a encarar de um modo 
novo os problemas básicos da sociedade, em primeiro lugar só podemos confiar em nos mesmos"(ELIAS,1999,p.9). Com "confiar em nós mesmos", Elias quer dizer que para compreendermos os problemas da sociedade, que é o que trata a sociologia, temos que nos distanciar de nós mesmos. Devemos nos considerar como parte ou membro da própria sociedade que estudamos. Encarando os seres humanos não como objetos estáticos separados de nós. Pois, os seres humanos também fazem parte do seu ambiente, da sua família e da sua sociedade, como nós investigadores fazemos parte de nossa. Portanto, conceitos como família e sociedade referem-se a grupos de seres humanos interdependentes que se interpenetram formando um nível de integração no qual as formas de organização, estruturas e processos não devem ser deduzidos das características biológicas e psicológicas que formam os indivíduos.

Entretanto, Norbert Elias não abandona totalmente aos paradigmas que orientavam em sua época a "ciência normal", entendida de acordo com a definição de Thomas Kuhn mencionada no início deste ensaio. Pelo contrário, ele dá continuidade a tradição do pensamento sociológico por dois motivos: primeiro porque centra sua discussão numa questão de grande importância para a sociologia que é sua autonomia frente as demais ciências, e o segundo motivo é o resgate que faz das idéias de Augusto Comte o "pai fundador da sociologia" incontestavelmente. Segundo Thomas Kuhn, não havendo transição para um novo paradigma, não há ruptura, e consequentemente não há "revolução científica". Mas metodológicamente o que nos aponta as contribuições de Elias? Apontam para uma melhor articulação da teoria sociológica de modo a garantir a sua autonomia, de repensar o seu problema resolvendo-o por um novo caminho que leva em consideração o seu caráter dinâmico e mutável. 
Referências Bibliográficas

Elias, Norbert. Introdução à sociologia. Lisboa : Edições 70, 1999

A Sociedade de Corte. Nova História, Lisboa, Editorial

Estampa,1995

O Processo Civilizador: uma História dos Costumes. Rio de Janeiro, Jorge Zahar Editores, 1990, volume I.

O Processo Civilizador: Formação do Estado e Civilização. Rio de Janeiro, Jorge Zahar Editores,1993, volume II.

Editores, 1994.

A Sociedade do Indivíduos. Rio de Janeiro, Jorge Zahar

Mozart - Sociologia de Um Gênio. Rio de Janeiro, Jorge Zahar Editores, 1995.

Os Alemães - A luta pelo poder e a evolução do habitus nos séculos XIX e XX. Rio de Janeiro, Jorge Zahar Editores, 1997.

Elias, Norbert e Scotson, John L. Os Estabelecidos e os Outsiders. Rio de Janeiro, Jorge Zahar Editores, 1999.

Kuhn, Thomas S. A estrutura das revoluções científicas. São Paulo : Editora Perspectiva, 1975. 